\title{
The Oxidative Stress Balance Measured in Humans with Different Markers, Following a Single Oral Antioxidants Supplementation or a Diet Poor of Antioxidants
}

\author{
Umberto Cornelli $^{1}$, Gianni Belcaro ${ }^{2}$, Annarosa Finco ${ }^{3 *}$ \\ ${ }^{1}$ Loyola University School of Medicine, Chicago, USA; ${ }^{2}$ University of Chieti, Chieti, Italy; ${ }^{3}$ Corcon International SRL, Parma, Italy. \\ Email: *finco.annarosa@libero.it
}

Received June 27 $7^{\text {th }}, 2011$; revised August $3^{\text {rd }}, 2011$; accepted August $19^{\text {th }}, 2011$.

\begin{abstract}
*
Four different markers of oxidative stress $[O S]$ (8-OHdG in urine, 8-Iso-PGF, hydroperoxides and carbonylated proteins in plasma, a new marker of antioxidant capacity $(A C)$ in plasma/urine/saliva, and hs-CRP were determined concomitantly in twelve apparently healthy volunteers. All the markers were determined at 8 am, $10 \mathrm{am}, 12 \mathrm{am}$ in three different moments: after a week of normal diet (baseline), after an acute supplementation with an antioxidant pool, and finally following a week of a diet poor in antioxidant. The supplementation of antioxidants determined a significant $(t$ test $p<0.05)$ decrease up to $12 \%$ of $8-O H d G$ in urine and up to $46 \%$ of carbonylated proteins in plasma, whereas hydroperoxides and 8-Iso-PGF were unmodified; the antioxidant capacity increased significantly ( $t$ test $p<0.05)$ up to $19 \%, 78 \%$, and $67 \%$, respectively in plasma, urine and saliva. Hs-CRP was unchanged.The diet poor in antioxidant caused significant increases ( $t$ test $p<0.01$ ) of hydroperoxides (up to 24\%), 8-Iso-PGF 23 (up to 69\%), carbonylated proteins (up to $76 \%$ ) and 8-OHdG (up to 16\%): hs-CRP increase reached $72 \%$ despite the levels were still within the normal range. Any reduction of soluble antioxidants activity in plasma was detected, whereas in urine and saliva a reduction of $45 \%$ and $38 \%$ respectively was shown. In conclusion, the antioxidant surplus determined by a single antioxidants pool administration seems to protect DNA and proteins from oxidation. On the contrary the shortage of antioxidant intake increases all the markers of OS, particularly those related to lipids and proteins, whereas the DNA seems to be protected more efficiently. The AC in plasma tends to be constant, and the limitation of antioxidants intake is followed by reduction of $A C$ in urine and saliva.
\end{abstract}

Keywords: 8-OHdG, 8-Iso-PGF, Hydroperoxides, Carbonylated Proteins, Soluble Antioxidant Test, Hs-CRP, Antioxidants

\section{Introduction}

The problem of the evaluation of oxidative stress (OS) and the use of antioxidant as remedies for many diseases is an overt matter. The epidemiological studies indicates that a constant fruits and vegetables intake reduces the incidence of cardiovascular diseases [1-3] and maybe of some cancer [4-7], whereas the use of food supplements containing vitamins usually end up with negative or controversial results [8]. However, most of the time in these studies the oxidant/antioxidant balance is not determined and positive or negative results may be due to reasons different from OS. Furthermore, different markers are used to determine the OS which may be addressed to different pathological conditions. The increase of hydroperoxides in plasma may give different indication than carbonylated or oxidized DNA (8-OHdG). Reviews are available reporting different methods to study the OS $[9,11]$ and antioxidant capacity [12], however, a direct comparison among the different method in relation to the intake of antioxidant are very scarce, as it is the kinetics of the antioxidant capacity of blood.

Recently a new very simple test, Soluble Antioxidant Test become available to determine the antioxidant capacity in plasma (PAT or plasma antioxidant test), urine (UAT or urine antioxidant test) and saliva (SAT or saliva antioxidant test) or any other body fluid in terms of $\mu \mathrm{mol}$ 
of Vitamin C. The method is based upon the capability of a given substrate to reduce Fe III.

This new test eliminates the interference of phosphates and sulfates contained in the samples, which interfere with the reaction binding $\mathrm{Fe}$ III and give false positive results.

The aim of the present study was to integrate the antioxidant power (measured by PAT,SAT and UAT) with the most common methods for OS evaluation, and to determine the behavior (kinetics) of antioxidants capacity in three different conditions: a) during a "normal" diet; b) after a single administration of a food supplement containing antioxidants; c) after a diet poor in antioxidants. In the same conditions the hs-CRP has been evaluated in plasma as a measure of the inflammatory status.

\section{Material and Methods}

Twelve apparently healthy volunteers $(6 \mathrm{M}$ and $6 \mathrm{~F})$ were admitted (age range between 23 and 35 years) among nurses and doctors of two dental offices. Exclusion criteria were smoking habit, a BMI $>25$ and $<20$ the use of any therapy, or food supplement intake. Furthermore, the subjects were inspected by the dentist to exclude any abnormality of tooth and oral mucosa. A written and informed consent was requested.

Experimental design: the trial was conducted in three subsequent weeks: a week of run-in, a week of "normal diet" followed by a single administration of a pool of antioxidants, and a finally a week of diet "poor in antioxidants". It was an open trial conducted in two dental offices.

Food intake assessment: volunteers were instructed by a nutritionist to fill up daily for the entire period (three weeks) a questionnaire for Food Intake Assessment (FIA) in which the most common 250 type of foods and beverages [13] were reported. From the questionnaire the nutritionist was calculating the quantity and frequency of the following 11 categories of foods: fruit, vegetables, cereals, meat, processed meat (ham, salami, sausages), fish, dairy products, legumes, alcohol, suit beverages, coffee/tea.

The energy intake was calculated as $\mathrm{MJ} /$ week according to standard tables [14].

The questionnaire was filled up for three weeks, in which the first week was considered as a run-in period, the second for the evaluation of the effect on oxidation/antioxidant balance of the usual diet, and the third for the evaluation of the effects of a diet poor in antioxidants. For this last week subjects were instructed to avoid foods containing high quantities of antioxidants (fruit, vegetables, coffee, tea, chocolate, and fruit juice of any kind). To equilibrate the energy reduction determined by these last foods, the subjects were allowed to increase the equivalent MJ through a surplus of cereals and meat.

Antioxidant administration: immediately after the second week, at the beginning of the third week, at 8 am all the volunteer were treated with one vial containing a pool of antioxidants composed by: Se [48 $\mathrm{mcg}$ ], Vitamin C [30 mg], Red fruits extract Richberry [150 mg], Zn [5 $\mathrm{mg}$ ], coenzyme $\mathrm{Q}_{10}[10 \mathrm{mg}$ ], L-cysteine $[8.7 \mathrm{mg}$ ], Vitamin E [15 mg], Vitamin B6 [1 mg], Vitamin A [400 $\mathrm{mcg}$ ], beta-carotene $[50 \mathrm{mcg}]$. The product was administered to measure the modification of OS markers and the dynamics of the "antioxidant capacity" in plasma, urine and saliva.

Experimental variables: number of weekly portions and energy intake (in terms of MJ) were measured on the base of FIA during each of the three weeks. In the morning of the day after the end of each week (see Table 1) blood, urine and saliva samples were taken at $8 \mathrm{am}, 10$ am and $12 \mathrm{am}$.

The following 8 different tests were applied in the samples of each subject to determine the OS or the antioxidant capacity:

The d-ROMs test in plasma as measure of hydroperoxides [15], a marker of the whole cellular oxidation; the test for isoprostanes (8-Iso-PGF $2 \alpha$ ) in plasma as measure of the oxidation of cellular membranes [16]; the test for 8-OHdG in urine as marker of DNA oxidation [17]; the test for carbonylated proteins in plasma as marker for oxidized proteins [18]; the test for hs-CRP that indicates a generic inflammatory condition [19]; the Soluble Antioxidant Test that measures the antioxidant capacity (AC) in plasma (PAT), urine (UAT) and saliva (SAT).

Blood sampling: blood samples were taken at 8 am, 10 am, 12 am as follows: after the first week (end of run-in); after the second week (8th day) at $8 \mathrm{pm}$, immediately before the antioxidants pool administration, and at $10 \mathrm{am}$ e 12 am (respectively after $2 \mathrm{~h}$ and $4 \mathrm{~h}$ after the administration to measure the effect of the antioxidant pool); after the third week characterized by the low antioxidant intake. Blood was drown following overnight fasting, from the brachial vein. Four samples of $5 \mathrm{ml}$ each were collected in heparinized tubes, and plasma was isolated by centrifugation. The determination of hs-CRP was carried out within 30 minutes from the collection); carbonylated proteins were determined within the day of collection), all the remaining plasma samples were frozen at $-80^{\circ} \mathrm{C}$ and the determinations were carried out within a week.

Urine collection: urine collection was requested three times in the same day of blood sampling from 6 am to 12 am. Samples were collected in $500 \mathrm{~mL}$ plastic containers as follows: elimination at 6 am of the urine of the night, followed by collections every two hours between $6-8$ 
Table 1. Flow chart of the trial. Samples of plasma, saliva and urine were taken at 8 am, 10 am and 12 am.

\begin{tabular}{|c|c|c|c|c|c|c|c|}
\hline \multirow{2}{*}{\multicolumn{2}{|c|}{ VARIABLES }} & \multicolumn{6}{|c|}{ DAYS } \\
\hline & & $1-7$ & 8 & $9-14$ & 15 & $16-21$ & 22 \\
\hline \multicolumn{2}{|c|}{ Diet } & Run-in & $\mathrm{N}$ & $\mathrm{N}$ & $\mathrm{L}$ & $\mathrm{L}$ & $\mathrm{L}$ \\
\hline \multicolumn{2}{|c|}{ FIA } & $*$ & * & $*$ & $*$ & $*$ & $*$ \\
\hline \multicolumn{2}{|c|}{$\mathrm{MJ}$} & $*$ & & $*$ & & $*$ & \\
\hline \multicolumn{2}{|c|}{ Antioxidants supplement } & & & & $*$ & & \\
\hline d-ROMs test & [plasma $]^{\mathrm{a}}$ & & * & & $*$ & & $*$ \\
\hline 8 -iso-PGF $2 \alpha$ & [plasma] & & $*$ & & $*$ & & $*$ \\
\hline 8-OHdG & [urine] $]^{\mathrm{a}}$ & & $*$ & & $*$ & & $*$ \\
\hline PAT & [plasma] & & $*$ & & $*$ & & $*$ \\
\hline UAT & [urine] & & * & & $*$ & & $*$ \\
\hline SAT & 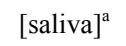 & & * & & $*$ & & $*$ \\
\hline Hs-CRP & [plasma] & & $*$ & & $*$ & & $*$ \\
\hline Carbonyl & [plasma] & & $*$ & & $*$ & & $*$ \\
\hline
\end{tabular}

*samples for all the determination were taken at $8 \mathrm{am}, 10 \mathrm{am}$, and $12 \mathrm{am}$.

am, 8 - 10 am, 10 - 12 am respectively. Samples were taken directly in the centre. The urine volume of each period was measured in the centre, and immediately after a sample of $20 \mathrm{~mL}$ was frozen at $-80^{\circ} \mathrm{C}$. During the morning of the sampling, subject were not allowed to take any kind of food of beverage, with the exclusion of water. Water was given to every subject in the same amount of $120 \mathrm{~mL}$ (one glass of water) at 8 am and 10 am (in total $240 \mathrm{~mL}$ ) to support the urine excretion. All the determinations in urine were carried out within the week of collection.

Saliva collection: at the moment of the determination (8 am, $10 \mathrm{am}, 12 \mathrm{am}$ ) immediately after each blood sampling subjects were requested to chew a $250 \mathrm{mg}$ cotton square to obtain a flow between 1.1 and $1.4 \mathrm{~mL} / \mathrm{min}$; this flow can be easily obtained biting gently the cotton square $60 \pm 2$ times in a minute $(1 \mathrm{bit} / \mathrm{sec})$.

Saliva flow was measured weighting the cotton square before and after biting. In case the flow was not between 1.1 to 1.4 , the test was repeated increasing or decreasing the number of bits accordingly. The antioxidant capacity was measured within three hour after the collection.

Statistical analysis: average values and standard deviation were calculated for all the variables, and the differences between the variables was measured using the $t$ test for interdependent data.

Correlation coefficient " $\mathrm{r}$ " was calculated on data concerning PAT and SAT, and the analysis of the variance (Anova) was applied to compare the weekly servings and MJ intake. Since the authors has large knowledge of d-ROMs test and PAT (which are routine determinations), the power was determined on the base of these tests. For both variables a samples of 10 cases may discriminate a difference of 1 SD (for an $\alpha 0.01$ for $1-\beta$ $1-90$ ) with a power $>0.9$. Consequently a group of 12 cases was considered sufficient for the aim of the study.

\section{Results}

The general characteristics of the subjects are reported in Table 2.

All the volunteers completed the trial and a part of three cases (1 M and $2 \mathrm{~F}$ ) of constipations and abdominal discomfort in the first days of the week of low antioxidant diet, no other complaints were recorded. These events were resolved by the initiative of the volunteers (they were doctors and nurses) with the increase of water intake.

Food intake and MJ: the number of servings and MJ intake of the three weeks are reported in Table 3.

During the low antioxidant diets, servings related to food rich of antioxidants (fruit, vegetables, etc.) were completely eliminated and the energy intake was compensated by a small increase of cereals, pulses and meat. However, the average values of weekly serving of these foods was not statistically significant (ANOVA $p<0.05$ ) since the energy compensation was dilutes among the different type of foods. The alcohol reduction was also consistent, and was related to wine and beer only, because liqueurs were not forbidden since their use was usually minimal.

OS and antioxidant capacity in plasm, saliva and urine. The variables related to OS are reported in Table 4. In

Table 2. General characteristics of volunteers. Mean values \pm SD.

\begin{tabular}{lrc}
\hline \multicolumn{2}{c}{ Variable } & \multicolumn{1}{c}{ Value } \\
\hline \multicolumn{1}{c}{ sex } & & $6 \mathrm{M} ; 6 \mathrm{~F}$ \\
Age & {$[$ years] } & $29 \pm 4.2$ \\
Body weight & {$[\mathrm{kg}]$} & $68 \pm 7.9$ \\
Height & {$[\mathrm{m}]$} & $1.67 \pm 0.08$ \\
BMI & {$\left[\mathrm{kg} / \mathrm{m}^{2}\right]$} & $24.1 \pm 0.70$ \\
\hline
\end{tabular}


Table 3. Number of weekly servings and the relative MJ intake during the observation periods. Mean values \pm SD.

\begin{tabular}{|c|c|c|c|c|}
\hline \multirow{2}{*}{ Type of food } & \multicolumn{3}{|c|}{ Periods } & \multirow{2}{*}{ ANOVA } \\
\hline & Run-in $[\mathrm{A}]$ & Normal diet [B] & Low antioxidant diet [C] & \\
\hline Fruits & $12.3 \pm 2.74$ & $12.2 \pm 2.72$ & $0 \pm 0.0$ & $\mathrm{~A}=\mathrm{B}<\mathrm{C}$ \\
\hline Vegetables & $9.6 \pm 1.78$ & $9.7 \pm 1.61$ & $0 \pm 0.0$ & $\mathrm{~A}=\mathrm{B}<\mathrm{C}$ \\
\hline Cereals & $23.7 \pm 2.78$ & $23.9 \pm 2.39$ & $25.1 \pm 2.39$ & $\mathrm{~A}=\mathrm{B}=\mathrm{C}$ \\
\hline Meat & $4.8 \pm 1.27$ & $4.9 \pm 1.08$ & $5.2 \pm 1.19$ & $\mathrm{~A}=\mathrm{B}=\mathrm{C}$ \\
\hline Processed meat ${ }^{\mathrm{a}}$ & $2.4 \pm 1.38$ & $2.5 \pm 1.38$ & $2.7 \pm 1.30$ & $\mathrm{~A}=\mathrm{B}=\mathrm{C}$ \\
\hline Fish & $1.9 \pm 0.67$ & $1.7 \pm 0.65$ & $1.8 \pm 0.58$ & $\mathrm{~A}=\mathrm{B}=\mathrm{C}$ \\
\hline Dairy products & $5.7 \pm 1.37$ & $5.4 \pm 1.31$ & $5.8 \pm 1.29$ & $\mathrm{~A}=\mathrm{B}=\mathrm{C}$ \\
\hline Legumes & $1.8 \pm 0.62$ & $1.6 \pm 0.67$ & $1.9 \pm 0.67$ & $\mathrm{~A}=\mathrm{B}=\mathrm{C}$ \\
\hline Alcohol & $11.3 \pm 2.84$ & $11.1 \pm 2.78$ & $1.5 \pm 1.73$ & $\mathrm{~A}=\mathrm{B}<\mathrm{C}$ \\
\hline Suit beverages & $8.0 \pm 1.04$ & $7.8 \pm 1.22$ & $0 \pm 0.0$ & $\mathrm{~A}=\mathrm{B}<\mathrm{C}$ \\
\hline Coffee/tea/Ch ${ }^{b}$ & $10.8 \pm 4.00$ & $10.6 \pm 3.73$ & $0 \pm 0.0$ & $\mathrm{~A}=\mathrm{B}<\mathrm{C}$ \\
\hline MJ & $66.5 \pm 2.24$ & $66.2 \pm 2.37$ & $67.4 \pm 2.43$ & $\mathrm{~A}=\mathrm{B}=\mathrm{C}$ \\
\hline
\end{tabular}

${ }^{\mathrm{a}}$ Ham, salami, sausages; ${ }^{\mathrm{b}}$ Chocolate.

Table 4. OS, antioxidant capacity, hs-CRP, urine volumes following different diets. Mean values \pm SD.

\begin{tabular}{|c|c|c|c|c|c|c|c|c|c|}
\hline \multirow{3}{*}{ Variables } & \multicolumn{9}{|c|}{ Periods } \\
\hline & \multicolumn{3}{|c|}{ Run-in Normal diet } & \multicolumn{3}{|c|}{ Antioxidant Normal diet } & \multicolumn{3}{|c|}{ Low antioxidant diet } \\
\hline & $8 \mathrm{am}$ & $10 \mathrm{am}$ & $12 \mathrm{am}$ & $8 \mathrm{am}$ & $10 \mathrm{am}$ & $12 \mathrm{am}$ & $8 \mathrm{am}$ & $10 \mathrm{am}$ & $12 \mathrm{am}$ \\
\hline $\begin{array}{l}\text { d-ROMs test } \\
\text { [plasma] } \\
\text { U.CARR. }\end{array}$ & $268 \pm 23.5$ & $280 \pm 10.4$ & $290 \pm 12.6$ & $254 \pm 23.0$ & $269 \pm 24.7$ & $280 \pm 21.0$ & $320^{\mathrm{a}} \pm 26.7$ & $340^{\mathrm{a}} \pm 27.5$ & $360^{\mathrm{a}} \pm 30.5$ \\
\hline $\begin{array}{c}\text { 8-iso-PGF2 } \alpha \\
\text { [plasma] } \\
\text { nmo } / \mathrm{L}\end{array}$ & $0.88 \pm 0.451$ & $0.79 \pm 0.421$ & $0.86 \pm 0.496$ & $0.93 \pm 0.558$ & $0.85 \pm 0.513$ & $0.87 \pm 0.419$ & $1.40^{\mathrm{a}} \pm 0.630$ & $1.34^{\mathrm{a}} \pm 0.630$ & $1.31^{\mathrm{a}} \pm 0.454$ \\
\hline $\begin{array}{l}\text { 8-OhdG } \\
\text { [urine] } \\
\text { nmol/L }\end{array}$ & $12.3 \pm 7.01$ & $13.8 \pm 8.01$ & $14.2 \pm 8.17$ & $11.7 \pm 6.33$ & $10.7 \pm 6.11$ & $10.3 \pm 5.07$ & $14.3^{\mathrm{a}} \pm 7.88$ & $13.4^{\mathrm{a}} \pm 5.73$ & $15.3^{\mathrm{a}} \pm 8.78$ \\
\hline $\begin{array}{c}\text { Carbonyl } \\
\text { [plasma] } \\
\mathrm{pmol} / \mathrm{mg} \text { protein }\end{array}$ & $49 \pm 31.5$ & $42 \pm 29.5$ & $50 \pm 38.2$ & $43 \pm 28.9$ & $36 \pm 21.7$ & $23^{b} \pm 14.6$ & $75^{\mathrm{a}} \pm 37.3$ & $84^{\mathrm{a}} \pm 42.7$ & $73^{\mathrm{a}} \pm 35.3$ \\
\hline $\begin{array}{c}\text { UAT } \\
\text { [urine] } \\
\mu \mathrm{mol} / \mathrm{L} \mathrm{Vit} \mathrm{C}\end{array}$ & $4270 \pm 654.5$ & $5115 \pm 635.0$ & $5125 \pm 504.4$ & $4135 \pm 600.8$ & $6117^{\mathrm{a}} \pm 647.8$ & $7185^{\mathrm{a}} \pm 728.0$ & $2690^{b} \pm 476.8$ & $2814^{b} \pm 387.5$ & $2126^{\mathrm{b}} \pm 269.7$ \\
\hline $\begin{array}{c}\text { SAT } \\
\text { [saliva] } \\
\mu \mathrm{mol} / \mathrm{L} \mathrm{Vit} \mathrm{C}\end{array}$ & $1100 \pm 123.3$ & $1317 \pm 103.6$ & $998 \pm 77.2$ & $1132 \pm 78.3$ & $1764^{\mathrm{a}} \pm 151.3$ & $1890^{\mathrm{a}} \pm 196.9$ & $760^{b} \pm 39.6$ & $815^{\mathrm{b}} \pm 54.6$ & $797^{b} \pm 76.7$ \\
\hline $\begin{array}{c}\text { hs-CRP } \\
\text { [plasma] } \\
\mathrm{mg} / \mathrm{L}\end{array}$ & $0.82 \pm 0.508$ & $0.80 \pm 0.510$ & $0.83 \pm 0.545$ & $0.76 \pm 0.468$ & $0.73 \pm 0.419$ & $0.74 \pm 0.472$ & $1.28^{\mathrm{a}} \pm 0.751$ & $1.38^{\mathrm{a}} \pm 0.764$ & $1.33^{\mathrm{a}} \pm 0.750$ \\
\hline $\begin{array}{l}\text { Urine volume } \\
\mathrm{mL}\end{array}$ & $140 \pm 37.1$ & $131 \pm 34.8$ & $126 \pm 22.6$ & $147 \pm 29.0$ & $139 \pm 28.5$ & $156^{\mathrm{a}} \pm 28.5$ & $153 \pm 28.0$ & $143 \pm 21.7$ & $132 \pm 20.8$ \\
\hline
\end{tabular}

${ }^{a}$ t test for interdependent data; the value are significantly higher $(p<0.01)$ vs same period of normal diet; ${ }^{b}$ test for interdependent data; the values are significantly lower $(p<0.01)$ vs same period of normal diet.

the run-in week no significant differences (ANOVA $p>$ $0.05)$ were found among the variables taken from 8 am to 12 am which were within the normality range.

The antioxidants pool administration (in the first day of the third week) ended up with different results for each marker.

The hydroperoxides (d-ROMs test) were practically unchanged compared to the baseline value, despite a small increase after $4 \mathrm{~h}(\mathrm{t}$ test $p>0.05)$, and plasmatic isoprostranes also were not significantly modified. 
DNA oxidation was reduced, since the values at 2 and $4 \mathrm{~h}$ were significantly lower ( $\mathrm{t}$ test $p<0.01$ ) respectively $-8 \%$ and $-12 \%$.

Carbonyl proteins in plasma were also lower at $2 \mathrm{~h}$ and $4 \mathrm{~h}$, respectively $-16 \%$ and $-46 \%$, but the reduction was statistically significant (t test $p<0.01$ ) after $4 \mathrm{~h}$ only.

The antioxidant capacity was modified in relation to the fluid analyzed:

PAT increased of $19 \%$ and $15 \%$ respectively 2 and $4 \mathrm{~h}$ after the administration ( $\mathrm{t}$ test $p<0.01$ );

UAT increased of $48 \%$ and $74 \%$ respectively at 2 and $4 \mathrm{~h}$ ( $\mathrm{t}$ test $p<0.01$ ). A concomitant increase of urinary volumes was observed in the $4 \mathrm{~h}$ collection $(126 \mathrm{~mL}$ vs $156, p<0.01$ ) corresponding to an increase of $24 \%$ of the baseline value, indicating that the increase of antioxidant elimination could be due partially to an increase of urinary excretion.

SAT was significantly higher at 2 and $4 \mathrm{~h}$ (t test $p<$ 0.01 ), respectively $56 \%$ and $67 \%$ more than the baseline value. PAT and SAT were found to be correlated in all the determinations with " $\mathrm{r}$ " values ranging between 0.732 and $0.888(p<0.001)$.

The hs-CRP was within the normal range in all the determination of the first two weeks.

After the third week of low antioxidant diet, all the markers of OS increased significantly ( $\mathrm{t}$ test $p>0.01$ ). The highest percent increases (as average increase of the determination at $8 \mathrm{am}, 10 \mathrm{am}$ and $12 \mathrm{am}$ ) were detected for isoprostanes and carbonyl proteins, respectively by $60 \%$ and $58 \%$, followed by a $23 \%$ average increase of hydroperoxides. DNA oxidation rise was instead very limited (7\% average increase). The hs-CRP also showed a substantial up-regulation (63\% average increase) despite the values were within the normality range $(<2$ $\mathrm{mg} / \mathrm{dL}$ ), and in two case only was exceeding $2 \mathrm{mg} / \mathrm{dL}$. The urine volume was almost constant.

\section{Discussion}

This research has some limitations due to type of subjects, who were selected among healthy people with high degree of knowledge in the matter under study and the measure of the AC thorough the soluble antioxidants only. This method does not detect liposoluble antioxidants, which are also important for the oxidant/antioxidant balance.

However, the outcomes of the experience gives many indications about the markers for OS, and the behavior of at least a part of the antioxidants reserve in the body.

Three main topics can be addressed: the OS markers in relation to the antioxidants intake, the soluble antioxidants bioavailability/kinetics, and finally the relation between OS and inflammation.
After the single administration of a pool of antioxidants, the reduction of oxidized proteins in plasma and oxidized DNA in urine was evident, whereas plasmatic isoprostanes and hydroperoxides remain constant. This could mean that the first line of protection by the soluble antioxidants network is directed mainly to protect proteins and DNA instead of phospholipids of the cellular membranes.

During the limitation of the antioxidants intake the substances more affected by oxidation are membrane lipids and proteins, whereas the DNA oxidation is minimal ( $7 \%$ increase), which may indicate that a very efficient mechanisms of protection of DNA is in place.

The whole picture suggests that in case of OS the soluble antioxidants network, proteins and lipids behave as a "buffer" to limit DNA oxidation.

Following a single administration of the antioxidants pool Isoprostanes and hydroperoxides showed no changes. However, in previous experiments [15] the antioxidants intake for a longer period of time (one week) was found to reduce significantly the plasma hydroperoxides levels.

The reduction of antioxidants intake for a week caused an increase of isoprostanes and hydroperoxides which may suggest that fruit and vegetables in combination with other antioxidants in foods and beverages (e.c. coffee, tea, fruit juice, chocolate) are helpful to avoid the OS progression.

The OS progression that seems to start from membranes lipids and move to the proteins (of cytosol, cellular membranes and circulating), and finally to the DNA.

The markers tested were capable to detect the OS with a consistent difference in terms of sensitivity, variability, cost and feasibility. The percentage increase was more evident for isoprostanes and carbonyl proteins that rise two/three times in comparison to hydroperoxides.

The picture could be different in case of a disease that may show specific pattern of OS; for instance diabetes could be different from cardiovascular diseases or from colon cancer (internal data).

The variability (coefficient of variability) was much higher for the isoprostanes, oxidized DNA and carbonylated proteins (respectively $61 \%, 57 \%, 65 \%$ ) compared to hydroperoxides $(9 \%)$. Consequently despite the lower sensitivity the d-ROMs test seems to be more solid.

For what concerns the cost and time needed for the determination, the d-ROMs test was the cheapest, since the cost of each determination cost was less than $20 €$, and the time needed for the execution was 6 minutes. All the other test were much more expensive and time consuming.

This means that for the description of groups of people 
(e.c. epidemiological studies) hydroperoxides measured with d-ROMs test could be more suitable to define cut-off limits and monitor the OS.

In relation to the kinetics of the $\mathrm{AC}$, for the first time there was a description of the dynamics in plasma, saliva and urine using the same method.

In normal conditions, plasma seems to maintain stable the soluble antioxidants reserve. The surplus deriving from antioxidants abundance tends to be eliminated rapidly throughout the two main excretory systems, saliva and urine, which both have the same daily volume production (about $1.5 \mathrm{~L}$ ).

The only difference between the two systems being that saliva theoretically allows the recycle of soluble antioxidant, whereas the urine does not. This behavior was confirmed after the antioxidants pool administration, where the increases in both saliva and urine were similar. During the low antioxidant intake the decrease was significantly higher in urine than in saliva (respectively $31 \%$ and $47 \%$; t test $p<0.01$ ) and may give support to the aspect of saliva recycling.

This may mean that saliva can be more efficient than urine as a mirror of the antioxidant capacity. In fact, the correlation between plasma and saliva was found significant in every determination, whereas the correlation between plasma and urine was not. Sweat and tears should be added to the list of possible excretion compartment, and the former is more important since it may the increase in relation to the temperature of the body and environment. Because of this one may expect that in case of fever or during summer the antioxidants excretion could be more active and the need of antioxidant could be much higher.

The increase of about $60 \%$ of soluble antioxidants elimination after the pool intake was concomitant to a $20 \%$ increase in the urinary flow. This last data can be interpreted also as a diuretic effect of the antioxidants pool.

This aspect should be analyzed more carefully in the light of the hypertension treatment, as blood pressure can be reduced by fruit and vegetable intake, and also by antioxidant supplements [24].

A consideration has to be addressed to the measure of the antioxidant capacity that was carried out with the Soluble Antioxidant Test only, without a direct comparison with other tests. Other common methods, such as the FRAP $[25,26]$, are based upon the reduction of Fe III to Fe II. However, these tests can give incorrect results, since the binding of phosphates and sulfates with Fe III do not allow its reduction to Fe II and may end up with false positive data. Plasma contains inorganic phosphate in sensible amount (between 2.5 to $4.5 \mathrm{mg} / \mathrm{dL}$ ) and all the body fluids can contain large quantity of phosphates (and sulfates), particularly saliva, where the amount of phosphates can fluctuate at least for one order of magnitude $(18-218 \mathrm{mg} / \mathrm{dL})$ [27]; the same is true for samples deriving from fruit and vegetables which have been extensively measured with FRAP [28].

The last aspect of the research is related to the behavior of hs-CRP as marker of inflammation.

The increase was evident and constant after a week of low antioxidants intake. This could mean that a reduction of antioxidant capacity can create the ground for inflammation. In other terms, the concept of "redox inflammatory status" $[20,21]$ emerges from the in vitro studies and get to the in vivo evidence. The findings that macrophages [22] and lipocytes [23] have tall-like receptors that once stimulated give rise to OS and inflammation seems to be confirmed in this study, giving body to the relation between oxidant/antioxidant equilibrium and the inflammatory condition.

However, all these findings need confirmation in long terms studies, and evaluation during different diseases in which the OS, antioxidant capacity and inflammatory markers should be measured concomitantly.

\section{REFERENCES}

[1] G. Buckland, C. A. González, A. Agudo, et al., "Adherence to the Mediterranian Diet and Risk of Coronary Heart Disease in the Spanish EPIC Cohort Study," American Journal of Epidemiology, Vol. 170, No. 12, 2009, pp. 1518-1529. doi:10.1093/aje/kwp282

[2] L. A. Bazzano, M. K. Serdula and S. Liu, "Dietary Intake of Fruit and Vegetables and Risk of Cardiovascular Disease," Current Atherosclerosis Reports, Vol. 5, No. 6, 2003, pp. 492-499. doi:10.1007/s11883-003-0040-Z

[3] B. J. Willcox, J. D. Curb and B. L. Rodriguez, "Antioxidant in Cardiovascular Health and Disease: Key Lessons from Epidemiological Studies," American Journal of Cardiology, Vol. 101, No. 10, 2008, pp. 75D-85D. doi:10.1016/j.amjcard.2008.02.012

[4] C. A. Gonzalez, "The European Prospective Investigation into Cancer and Nutrition (EPIC)," Public Health Nutrition, Vol. 9, No. 1a, 2006, pp. 124-126. doi:10.1079/PHN2005934

[5] A. Koushik, D. J. Hunter, D. Spiegleman, et al., "Fruits, Vegetables and Colon Cancer Risk in a Pooled Analysis of 14 Cohort Studies," Journal of the National Cancer Institute, Vol. 99, No. 19, 2007, pp. 1471-1483. doi:10.1093/jnci/djm155

[6] P. Boffetta, E. Couto, J. Wichmann, et al., "Fruit and Vegetable Intake and Overall Risk in the European Prospective Investigation into Cancer and Nutrition (EPIC)," Journal of the National Cancer Institute, Vol. 102, No. 8, 2010, pp. 529-537. doi:10.1093/jnci/djq072

[7] F. L. Büchner, H. B. Bueno-de-Mesquita, M. M. Ros, et 
al., "Variety in Fruit and Vegetable Consumption and the Risk of Lung Cancer in the European Prospective Investigation into Cancer and Nutrition," Cancer Epidemiology, Biomarkers \& Prevention, Vol. 19, No. 9, 2010, pp. 2278-2286.

[8] H. Y. Huang, B. Caballero, S. Chang, et al., "The Efficacy and Safety of Multivitamin and Mineral Supplement Use to Prevent Cancer and Chronic Disease in Adults: A Systematic Review for a National Institute of Health State-of-the-Science Conference," Annals of Internal Medicine, Vol. 145, No. 5, 2006, pp. 372-385.

[9] S. Mayne, "Antioxidant Nutrients and Chronic Disease: Use of Biomarkers of Exposure and Oxidative Stress Status in Epidemiologic Research," Journal of Nutrition, Vol. 133, No. 3, 2003, pp. 933S-940S.

[10] E. S. Hwang and G. H. Kim, "Biomarkers for Oxidative Stress Status of DNA, Lipids, and Proteins in Vitro and in Vivo Cancer Research," Toxicology, Vol. 229, No. 1-2, 2006, pp. 1-10. doi:10.1016/j.tox.2006.10.013

[11] M. Valko, D. Leibfritz, J. Moncol, et al., "Free Radicals and Antioxidants in Normal Physiological Functions and Human Disease," The International Journal of Biochemistry \& Cell Biology, Vol. 39, No. 1, 2007, pp. 44-84. doi:10.1016/j.biocel.2006.07.001

[12] E. Niki, "Assessment of Antioxidant Capacity in Vitro and in Vivo," Free Radical Biology \& Medicine, Vol. 49, No. 4, 2010, pp. 503-515. doi:10.1016/j.freeradbiomed.2010.04.016

[13] FIA. http://www.fia-db.com/-2003

[14] National Research Institute for Food and Nutrition, "Food Composition," EDRA Medical Publishing \& New Media, Milan, 2002.

[15] U. Cornelli, R. Terranova, S. Luca, et al., "Bioavailability and Antioxidant Activity of Some Food Supplements in Men and Women Using the D-Roms Test as a Marker of Oxidative Stress," Journal of Nutrition, Vol. 131, No. 12, 2001, pp. 3208-3211.

[16] S. A. Dillon, G. M. Lowe, D. Billington and K. Rahman, "Dietary Supplementation with Aged Garlic Extract Reduces Plasma and Urine Concentration of 8-Iso-Prostaglandin F(2 Alpha) in Smoking and Nonsmoking Men and Women," Journal of Nutrition, Vol. 132, No. 9, 2002, pp. 168-171.

[17] S. Mei, Q. Yao, C. Wu and G. Xu, "Determination of Urinary 8-Hydroxy-2-Deoxyguanosine by Two Approaches-Capillary Electrophoresis and GC/MS: An Assay for in Vivo Oxidative DNA Damage in Cancer Patients,"
Journal of Chromatography B: Analytical Technologies in the Biomedical and Life Sciences, Vol. 827, No. 1, 2005, pp. 83-87.

doi:10.1016/j.jchromb.2005.04.001

[18] H. Buss, T. P. Chan, K. B. Sluis, et al., "Protein Carbonyl Measurement by a Sensitive Elisa Method," Free Radical Biology \& Medicine, Vol. 23, No. 3, 1997, pp. 361-366. doi:10.1016/S0891-5849(97)00104-4

[19] N. Rifai and P. M. Ridker, "High-Sensitivity C-Reactive Protein: A Novel and Promising Marker of Coronary Heart Disease," Clinical Chemistry, Vol. 47, No. 3, 2001, pp. 403-411.

[20] I. Rahman, S. K. Biswas and P. A. Kirkham, "Regulation of Inflammation and Redox Signaling by Dietary Polyphenols," Biochemical Pharmacology, Vol. 72, No. 11, 2006, pp. 1439-1452. doi:10.1016/j.bcp.2006.07.004

[21] M. Macarrone and B. Brüne, "Redox Regulation in Acute and Chronic Inflammation," Cell Death \& Differentiation, Vol. 16, No. 8, 2009, pp. 1184-1186. doi:10.1038/cdd.2009.65

[22] Y. I. Miller, S. H. Choi, L. Fang and R. Harkewicz, "Toll-Like Receptors-4 and Lipoprotein Accumulation in Macrophages," Trends in Cardiovascular Medicine, Vol. 19, No. 6, 2009, pp. 227-232. doi:10.1016/j.tcm.2010.02.001

[23] A. Schäffler and J. Schölmerich, "Innate Immunity and Adipose Tissue Biology," Trends in Immunology, Vol. 31, No. 6, 2010, pp. 228-235.

[24] E. L. Schiffin, "Antioxidant in Hypertension and Cardiovascular Disease," Molecular Interventions, Vol. 10, No. 6, 2010, pp. 354-362.

[25] I. F. Benzie and J. J. Strain, "The Ferric Reducing Ability of Plasma (FRAP) as a Measure of Antioxidant Power: The FRAP Assay," Analytical Biochemistry, Vol. 239, No. 1, 1996, pp. 70-76. doi:10.1006/abio.1996.0292

[26] H. R. Suma, K. Prabhu, R. P. Shenoy, et al., "Estimation of Salivary Protein Thiols and Total Antioxidant Power of Saliva in Brain Tumor Patients," Journal of Cancer Research and Therapeutics, Vol. 6, No. 3, 2010, pp. 278-281. doi:10.4103/0973-1482.73357

[27] W. M. Edgar, "Saliva: Its Secretion, Composition and Function," British Dental Journal, Vol. 172, No. 8, 1992 pp. 91-96. doi:10.1038/sj.bdj.4807861

[28] M. H. Carlsen, B. L. Halvorsen, K. Holte, et al., "The Total Antioxidant Content of More than 3100 Foods, Beverages, Spices, Herbs and Supplement Used Worldwide," Nutrition Journal, Vol. 9, No. 3, pp. 9-13. 